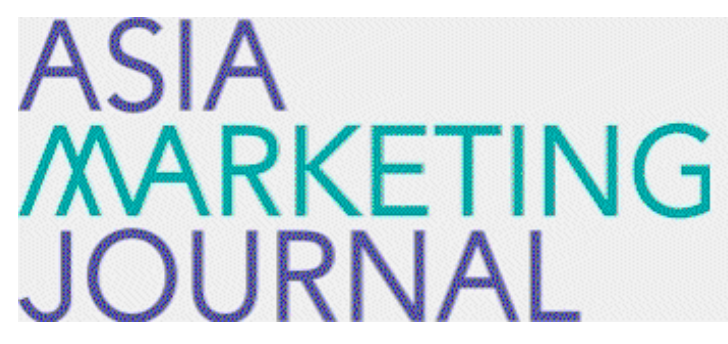

ASIA MARKETING JOURNAL

Volume 17 | Issue 1

Article 2

4-30-2015

\title{
How to Build a Learning Capability for Innovation? A Framework of Market-Based Learning Process
}

Hyun Jung Lee

Jeong Eun Park

Jae Hyun Pae

Follow this and additional works at: https://amj.kma.re.kr/journal

Part of the Marketing Commons

\section{Recommended Citation}

Lee, Hyun Jung; Park, Jeong Eun; and Pae, Jae Hyun (2015) "How to Build a Learning Capability for Innovation? A Framework of Market-Based Learning Process," Asia Marketing Journal: Vol. 17 : Iss. 1 , Article 2.

Available at: https://doi.org/10.15830/amj.2015.17.1.27

This Article is brought to you for free and open access by Asia Marketing Journal. It has been accepted for inclusion in Asia Marketing Journal by an authorized editor of Asia Marketing Journal. 


\title{
How to Build a Learning Capability for Innovation? A Framework of Market-Based Learning Process*
}

\author{
Hyun Jung Lee** \\ Jeong Eun Park*** \\ Jae Hyun Pae $\mathrm{P}^{* * * *}$
}

\begin{abstract}
Learning organization has been an important issue in both management and marketing areas. Also learning capability is a key construct of innovation process in a firm. Especially, in marketing context, several researchers have studied market-based learning and its relation with performance. Previous studies have shown that market-based learning has a positive impact on overall firm performance. However, there has been inconsistency in the concept of market-based learning itself and its relationships with antecedents and consequences. Given this conflicting and inconsistent results of previous research, this study has two main objectives. First, this paper proposed a conceptual framework that marketbased learning has two types of processes and each types of market-based learning will generate different types of performance. Second, the mediating role of marketing capability in learning-performance link is proposed. The proposed conceptual framework shows that organizations which have marketbased learning for innovation management can enjoy ambidextrous firm performance on both side of effectiveness and efficiency via marketing capability. Moreover our research model proposes key drivers of market based organizational learning.
\end{abstract}

Key words: Organizational Learning, Marketing Capability, Innovation, Market-based Learning

With the growing realization of organizational learning's (hereafter OL) relevance to firm competitiveness, recently there have been in- creasing managerial and scholarly interests on the concept of organizational learning in marketing perspective, so called market-based learn-

\footnotetext{
This paper is prepared for the submission to Asia Marketing Journal

** Lecturer, College of Business Administration, Ewha Womans University (hjworld@ewhain.net)

*** Associate Professor, College of Business Administration, Ewha Womans University (jepark@ewha.ac.kr), Corresponding Author

**** Professor, College of Business Administration, Ewha Womans University (pae@ewha.ac.kr)
} 
ing (e.g., Day 1994; Sinkula 1994; Moorman 1995: Slater and Narver 1995; Sinkula, Baker, and Noordewier 1997). Although conceptual contributions to the OL literature over the past four decades have been extensive in management context (e.g., Simon 1953; Argyris and Schon 1978; Hedberg 181; Fiol and Lyles 1985; Huber 1991), market-based organizational learning (hereafter xMBOL) from marketing context is presently under employed.

Marketing strategy researchers commonly hold a belief that a key factor for achieving superior business performance is to gain a competitive advantage and make it sustainable (Day 1994). To achieve a sustainable competitive advantage, organizations must develop some capabilities which are difficult to be imitated by its competitors (Barney 1991).

The development of capability of learning in the organization has been identified as either effective or efficient ways in which a firm can achieve a competitive advantage (Day 1994; Sinkula 1994). Companies such as Apple, Nike, and Mercedes Benz are commonly in positions of having dominant market share. It can be easily recognized that the performance of such companies is more effective, rather than efficient due to their differentiation or innovation driving core competency. On the other hand, companies like Southwest Air, Dell Computer, and Wall Mart are well known as cost efficiency driving companies. March (1991) addresses the problem of trade-off relationship between ef- fectiveness and efficiency. He defined effectiveness with the concept of search, variation, risk raking, experimentation, and innovation compare to efficiency. Then one can ask; is a firm with dominant market share or innovation (effectiveness) able to be dominant at the financial profitability (efficiency) at the same time? Or is a firm that focuses its strategy on cost efficiency be able to achieve also superiority in effectiveness performance such as innovation?

Organizational learning theory (e.g., March 1991) presents the search for innovations as part of the organizational learning process through which firms attempt to solve its problems by balancing exploitation and exploration. Innovation consists of implementing creative ideas through gathering the market information and sharing it within organization. Therefore it is closely related to organizational learning (Griffin 1997; Barczak and Crossan 1995; Wakasugi and Koyata 1997; O'connor 1998). Such studies indicate that learning is a key driver for innovations for the organization (McKee 1992; Alegre and Chiva 2007; Methe et al. 1997; Michael and Palandjian 2004).

Having discussed on this issue, this study addresses three important gaps in the previous MBOL literatures. First, in searching for an appropriate operational definition of MBOL, we found little consensus among researchers (Garvin 1998: Saban, John, Conway, and Graham 2000). Based on earlier works, here we propose the 
conceptual framework of two levels of MBOL. One level of MBOL enables gathering and interpreting the market knowledge, called "lower level learning" (market sensing) and another level related to sharing and memorizing the acquired knowledge, which we named "higher level learning" (value creation). We expect that the absence of either of the two learning steps leads to deficiency in achieving two areas of firm's performance. Second, prior researches on MBOL show mixed results about the influence of the learning on firm's performance (e.g., Hanvanich, Sivakumar, and Hult 2006; Paladino 2008: Kale and Singh 2007). In this paper we suggest that there might be some missing mediators between learning and performance. We propose marketing capability as a good candidate of mediators and provide a theoretical explanation of its role between learning and performance in both effectiveness and efficiency. Researchers revealed that firm performance is determined by how effectively and efficiently the firm's strategy is implemented (Olson, Slater and Hult 2005; Galbraith and Kazanjian 1986). The process of implementing strategies addresses how marketing activities are accomplished (Slater and Olson 2001; Walker and Ruekert 1987). How well the marketing activities are accomplished is influenced by how they are organized (Vorhis and Morgan 2003; Weitz and Anderson 1981) and the specific behaviors the organization undertakes regarding customer orientation, innovation, and market learning (e.g., Chen 1996; Deshpande, Farley, and Webster 1993; Day and Nedungadi 1984; Gatingnon and Xuereb 1997). Third, we found a lack of research in marketing that shows how to enhance learning process. In this paper we suggest several important determinants of MBOL.

This study attempts to fill these research gaps. In doing so, we extend the literature on MBOL and marketing capability. The research model we depict in Figurel illustrates the thesis of this study; that is, (1) the relationship between MBOL and firm performance is mediated by marketing capability (2) to build up MBOL capability, two determinants of absorptive capacity and management support are needed. The key contribution of this study is that it develops and proposes a framework for conceptualizing MBOL. Furthermore, this article gives important implications that marketing capability will play an important mediating role in enhancing both effectiveness and efficiency dimensions of firm performance in the learning-performance link.

We begin this study by reviewing the previous studies of OL and highlighting some deficiency of the previous works. Then we propose a conceptual framework by describing and conceptualizing MBOL, and discuss the theoretical backgrounds of marketing capability and its impact on the firms' performance. Based on the literature review, the hypotheses about determinants of MBOL will be followed. Next, 
we report the results of an empirical study that tests these hypotheses. Finally we conclude by discussing our findings and offering suggestions for managers and marketing scholars.

\section{Market-based Organizational Learning}

Since Fiol and Lyles (1985) mentioned that there had been lack of consistency of the theory or model of OL, there have been many studies to provide more concrete and sophisticated definition and theory by researchers (e.g., Huber 1991; Sinkula 1994; Slater and Narver 1995; Moorman and Miner 1997). Sinkula (1994) has brought the concept of OL to the marketing literature from management literature and addressed the difference between OL and MBOL. He also provided evidence of the importance of MBOL in the organizations. He proposed that MBOL has relationship with organizational structure change, so that the more decentralized, the more importance of learning might be addressed. Furthermore, learning can lead to the structural change of organizations.

More recently a number of researchers have emphasized the relevance of organizational learning in several marketing areas, such as strategic marketing and marketing management (e.g., Barker and Sinkula 1999). Many researchers (e.g., Day 1994; Sinkula 1994) view MBOL as crucial to the process of developing market knowledge such as a driving force of action in and governance of market-oriented organizations (Bell, Whitwell and Lukas 2002).

Although there is some variance in the definitions of learning, OL scholars in marketing typically conceptualize OL as market information processing including four primary constructs; information generation, dissemination, interpretation, and memory (Day 1994; Dixon 1992; Huber 1991; Sinkula 1994; Zuboff 1988). Information generation and dissemination activities are more overt, explicit, and observable. Conversely, interpretation and memory are more tacit, covert, and unobservable. Their tacit nature particularly in the case of interpretation makes them difficult not only to observe but to communicate relative to more explicit tasks and information (Nonaka 1991; Sinkula, Baker and Noordewier 1997).

\subsection{Two types of learning}

In building concept of MBOL, we found there are two types of learning (Fiol and Lyles 1985; Slater and Narver 1995; Senge 1990). Fiol and Lyles (1985) suggested them as level of learning. They revealed that lower level learning occurs within a given organizational structure, a given set of rule and the learning usually are of short duration and impact only part of what the organization does whereas higher level learning aims at adjusting overall rules and norms rath- 
er than specific activities or behaviors.

Slater and Narver (1995) also stated that there are two different types of learning which are "Adaptive learning" and "Generative learning". Adaptive learning, in their conceptual research, is requential, incremental, and focused on issues or opportunities that are within the traditional scope of the organization's activities which has consistent concept with "Lower level learning" of Fiol and Lyles (1985). On the other hand, Generative learning requires the development of a new way of looking at the world based on an understanding of the systems and relationships that link key issues which has consistent view with "Higher level learning" of Fiol and Lyles (1985). Sinkula (1994) also have conceptualized the MBOL as two levels of early stages of knowledge development and later stages of knowledge development and addressed the per- fect market-based learning can be said only if the latter stages of learning is completed.

Hence we declare that those two types of learning seem to be explicitly different in their concepts, roles and characteristics (Sinkula 1994; Hurley and Hult 1993; Fiol and Lyles 1985; Bell, Whitwell and Lukas 2002). However most researchers defined and measured the MBOL process - knowledge generation, dissemination, transfer, and memory - without considering levels or types (e.g., Kale and Sigh 2007; Zhou, Im and Tse 2005; Sinkula 2002).

Table 1 summarizes the characteristics of knowledge and organizational behavior for each level of MBOL. Information or knowledge that is first collected by marketing and relevant department is more analytic and explicit in the contents so that it is easy to share the knowledge for the members of inter marketing

$\langle$ Table 1〉 Different Perspective of the Researches

\begin{tabular}{cll}
\hline & \multicolumn{1}{c}{ Culture } & \multicolumn{1}{c}{ Process } \\
\hline \multirow{2}{*}{$\begin{array}{c}\text { Resources and } \\
\text { capability }\end{array}$} & Hurley and Hult (1998) & $\begin{array}{l}\text { Sinkula (1994) } \\
\text { Slater and Narver (1995) } \\
\end{array}$ \\
& & $\begin{array}{l}\text { Sinkula, Baker and Noordewier (1997) } \\
\text { Saban, Lanasa, Lackman and peace(2000) } \\
\text { Sinkula (2002) }\end{array}$ \\
\hline & Fiol and Lyles (1985) & Huber (1991) \\
& Moorman and Miner (1995) & Adams, Day and Dougherty (1998) \\
& Claycomb and Miller (1999) & Kale and Singh (2007) \\
Organizational & Marinova (2004) & \\
Behavior & Eisenstein and Hutchinson (2006) & \\
& Hanvanich, Sivakumar, Hult (2006) & \\
& Akgun, Lynn and Byrne (2006) & \\
& Paladino (2007) & \\
& Barker and Sinkula (2007) & \\
& Paladino (2008) & \\
\hline
\end{tabular}


departments. This explicit knowledge becomes more complex, applied and tacit knowledge in the process of interpretation and memorization into the organization wide. If the knowledge is embedded as memory of organization, this can serve as organizational culture or structure which can generate long term performance, subculture, and norm. Hence we can propose that lower level learning pursues more short term behavioral changes whereas higher level learning can affect long term performance or change.

\subsection{Learning as culture}

More recently, many researchers view MBOL as a culture rather than simple behavioral processes of knowledge generation, dissemination, interpretation and memory (e.g., Marinova 2004; Hanvanich, Sivakumar, and Hult 2006; Barker and Sinkula 2007). The studies that view MBOL as a culture insists that learning orientation should be embedded in the culture of organization and in decision rules and affect market vigilance and action (Day 1990; Hurly and Hult 1998; Paladino 2007).

\subsection{Learning as capabilities of competitive advantage}

There has emerged a large and growing literature on MBOL that tried to show how MBOL confers competitive advantage through its interplay with marketing capabilities and outcomes (e.g., Baker and Sinkula 1999; Slater and Narver 1995). They consider MBOL as a core competency pertaining to external foci, less visible than most internally focused MBOL competencies and is not easily imitable by competitors because there market knowledge is more equivocal and embedded as organization memory (Sinkula 2002).

Various views from previous studies suggesting a positive link between MBOL and performance have been put forth. Learning has been suggested as a complex resource of the firm that can be used to create competitive advantage and, ultimately, superior performance (Hunt, and Morgan 1996). Dickson (1996) suggests that learning enables firms to sustain competitive advantages by continuously improving market information-processing activities faster than the competition.

Sinkula (1994) also provided evidence that MBOL results in the fundamental bases of competitive advantage and developing these bases of competitive advantage requires what he refers to subsequently as "higher-order learning".

Here we conceptualize MBOL as follows;

"MBOL is market information process involving knowledge acquisition, dissemination, transfer, and memory, which may play as core competency to outperform competitors, and this sustainable positional advantage can be obtained only when the learning culture is embedded in the organization. Knowledge acquisition and dissemination processes 
involve rather intra departmental level of learning which refers "adaptive learning", and knowledge transfer and memory processes involve inter departmental level of learning which refers "generative learning".

Table 2 summarizes the different perspectives of the prior researches.

We also expect that effective intra department level learning to enhance inter departmental level learning as investigated in literatures that view learning as process (e.g., Sinkula 1994; Huber 1991). The foregoing leads to the following hypothesis:

H1: Adaptive learning will positively influence generative learning.

The relationship between each level of learning and marketing capability, firm performance and other antecedents will be discussed at the next section.

\section{Key Antecedents of MBOL: Absorptive Capacity and Management Support}

Fiol and Lyles (1985) suggested that there are four contextual factors affect the probability that learnin g will occur; corporate culture conducive to learning, strategy that allows flexibility, an organizational structure that allows both innovativeness and new insights, and the environment.

Not many studies have empirically investigated the factors enhancing MBOL (Narver and Slater 1995: Barker and Sinkula 2007; Kale and Singh 2007). Table 3 summarizes the antecedents in prior researches, which we have classified into cultural factors and structural factors.

Many of the studies which try to identify the enhancing factors of learning show that cultural factors such as entrepreneurship (Slater and Narver 1995; Chonko, Jones, Roberts, and

〈Table 2〉 Adaptive vs Generative Learning

\begin{tabular}{cll}
\hline & \multicolumn{1}{c}{ Adaptive learning } & \multicolumn{1}{c}{ Generative learning } \\
\hline \multirow{2}{*}{ Knowledge } & Analytical knowledge & Applied knowledge \\
characteristics & & Tacit knowledge \\
& Exploitative knowledge & Equivocal knowledge \\
& Explorative knowledge \\
\hline \multirow{3}{*}{$\begin{array}{c}\text { Organizational } \\
\text { behavior }\end{array}$} & Explicit activities & Explorative learning behavior \\
characteristics & Inter departmental & Tacit activities \\
& Marketing department level learning & Qualitative process \\
& Observable process and activities & Ontra departmental \\
\hline \multirow{2}{*}{ Orientation } & Short term performance & Unobservable processes and activities \\
& Behavioral change & Long term performance \\
& & Culture, norm change \\
\hline
\end{tabular}


Dubinsky 2002; Zhou, Yim and Tse 2005; Brockman and Morgan 2003; Weerawardena 2003), market orientation (Slater and Narver 1995; Nobel, Sinha and Kumar 2002; Barker and Sinkula 2007), and top management characteristics (Farell 2000) influences market-based learning of organization. There are also several researches which provide the evidence of structural factors of organization enhancing MBOL (Slater and Narver 1995; Claycomb and Miller 1999).

Organizational culture is defined by Deshpande and Webster (1989, p.4) as "the pattern of shared values and beliefs that help individuals understand organizational functioning and that provide norms for behavior in the organization." It can affect the firms' choice of outcomes and the means to achieve these outcomes (Cameron and Freeman 1991; Deshpande, Farley, and Webster 1993; Mooreman 1995).

Management support is expected to be a cultural factor which enhances efficient MBOL. It is argued that senior managers shape the direction of the organization and its values (Webster 1988). In learning-oriented organizations, managers support staff develop and share insights and innovations, so that they emphasis on learning the organization more tend to have capability of learning or learning orientation (Bennett and O'Brien 1994; Farrell 2000). Slater and Narver (1995, p69) also show that leaders "share information readily, motivate people to learn, and challenge their own assumptions and mental models'. The importance of leadership in shaping the values and culture of an organization has been discussed by several researchers (e.g., Webster 1988; Nonaka 1991). Management support refers to the extent that is encouraged by management of transferring and using knowledge (Farell 2000). We expect that the organizational culture that is supportive of MBOL will directly influence the learning capacity of both department (adaptive learning) and overall organization (generative learning).

Another important factor that influences MBOL is organizational absorptive capacity. In recent years, many of management researchers have studied absorptive capacity in OL and transferring knowledge. The absorptive capacity is referred as understanding the value of new information, assimilating it, and applying it to commercial ends (Cohen and Levinthal, 1990). Absorptive capacity could be supported by its relevant technology-based capability such as information systems. (Mowery, Oxley and Silverman 1996). Hence, absorptive capacity is rather an issue of tangible and explicit skills compared to learning capability. Once the absorptive capacity has been achieved by organization, it is embedded in the organization as structure and serves as core capability in OL in resource based view. Szulanski (1996) found that lack of absorptive capacity may results in barrier to knowledge transfer within organization. Hence we expect the organization which has absorptive capacity will also have market-based 
〈Table 3〉 Antecedents of Market-based Learning in Prior Researches

\begin{tabular}{|c|c|c|}
\hline & Variables & Research \\
\hline Culture & $\begin{array}{l}\text { Entrepreneurship } \\
\text { Market Orientation } \\
\text { Learning Orientation } \\
\text { Leadership Style } \\
\text { Top Management behavior (Risk/ Emphasis) } \\
\text { Culture } \\
\text { Cohesiveness }\end{array}$ & $\begin{array}{l}\text { Slater and Narver (1995) } \\
\text { Moorman (1995) } \\
\text { Sinkula, Baker and Noordewier (1997) } \\
\text { Chonko, Jones, Roberts and Dubinsky (2002) } \\
\text { Brockman and Morgan (2003) } \\
\text { Weerawardena (2003) } \\
\text { Zhou, Yim and Tse (2005) } \\
\text { Barker and Sinkula (2007) }\end{array}$ \\
\hline $\begin{array}{c}\text { Climate } \\
\text { (Structure) }\end{array}$ & $\begin{array}{l}\text { Organic Structure } \\
\text { Organizational structure } \\
\text { Decentralized Strategic Planning } \\
\text { Existing Knowledge } \\
\text { Strategy Change } \\
\text { Absorptive Capacity } \\
\text { Prior Knowledge }\end{array}$ & $\begin{array}{l}\text { Slater and Narver (1995) } \\
\text { Claycomb and Miller (1999) } \\
\text { Brockman and Morgan (2006) } \\
\text { Kale and Singh (2007) } \\
\text { Cohen and Levinthal (1990) }\end{array}$ \\
\hline
\end{tabular}

learning capability. The above discussion leads to the following propositions:

H2: Management support of learning will enhance both types (adaptive and generative) of learning

H3: Absorptive capacity of learning will enhance both types (adaptive and generative) of learning

\section{Marketing Capability as a Core Mediator in Learning- Performance Link}

\subsection{Market Learning and Firm Performance}

Firm performance can be measured and judged on various types. Performance is a joint function of potential return from an activity and an organization's present competence in that activity at the short-term and long-term basis (Özsomer and Gençtürk 2003; Madhavan and Grover 1998; Hoegl et al. 2007). Thus, we conceptualized the performance with two types; whether it has a long- or short-term view of the outcomes (effectiveness and efficiency).

Effectiveness type of firm performance captures rather long-term outcome, which is commonly measured by such items as market share, innovativeness of new products, and product quality compared with that of competitors. Efficiency type captures short-term outcome in relation to the resources invested, which is commonly measured by such items as profitability of sales and return on investment.

We expect that each types of MBOL differ in influencing these two types of performance 
depending on its knowledge collected and managed. Özsomer and Gençtürk (2003) found that exploration of market learning capability enhances the effectiveness of performance, whereas exploitation of market learning enhances the efficiency of performance. Their result implicates that what is good in the long run is not always or necessarily good in the short run. Narver and Slater (1995) and Fiol and Lyles (1985) mentioned that the desired consequence of adaptive learning is a particular behavioral outcome or level of performance because the focus of this learning is on the immediate effect on particular activity or facet of the organization whereas generative learning is a more cognitive process which often is the result of repetitive behavior. We propose that adaptive learning has a positive impact on short-term performance indicated by efficiency. This is because knowledge stocked by generative learning is less clear and more to be customized if other departments try to utilize the knowledge compared to the knowledge acquired from adaptive learning so that it is needed more time to generate outcome. Based on the above dialectic, the following two hypotheses are proposed:

H4: Adaptive learning will positively influence firm's efficient performance

H5: Generative learning will positively influence firm's effective performance

\subsection{Marketing Capability}

The development of marketing capabilities has been identified as one of the primary ways firms can achieve a competitive advantage (Day and Wensley, 1988). Marketing capability refers to organizational ability to create various marketing programs, to change its program frequently, and to implement marketing programs in a timely fashion. Vorhies and Morgan (2003) measured it with two sub dimensions. One is specialized marketing capability which captures specific marketing mix based work routines and the other is architectural marketing capability which captures marketing strategy formulation and execution work routines.

The focus of the definition of marketing capability is on "transforming marketing inputs to outputs", which implies the ability of utilization of the existing marketing resources. Hence, the more useful resources and capabilities are embedded in the organizations through market learning, the superior they might have marketing capability (Day 1994; Menon and Varadarajan 1992).

Researchers have revealed the important factors to affect the marketing capabilities (e.g., Day 1994; John and Martin 1984; Walker and Ruekert 1987; Keller 1994). One of the primary factors is organization's information processing capabilities (Menon and Varadarajan 1992; Keller 1994; Vorhies 1998). Marketing departments that have higher information processing 
capabilities will be able to develop more effective capabilities as they exchange information with other work group and disseminate that information throughout the organization (Kohli and Jaworski 1990; Slater and Narver 1995). Vorhies (1998) found that to be able to develop needed capabilities in marketing department, market information processing capabilities must be well-developed. More recently Vorhies and Harker (2000) investigated the importance of learning processes in the marketing capability development process. Marketing capabilities are developed through learning processes when the firm's employees repeatedly apply their knowledge to solving the firm's marketing issues (Day, 1994; Grant 1996, Weerawardena 2003; Vorhis 1998). Accordingly, we propose the following hypothesis:

H6: Both adaptive and generative learning will positively influence marketing capability

Marketing capability of the firm has been predicted as a major determinant of organizational effectiveness (Vorhies 1998). Firms that emphasize market information gathering, promotion, pricing program effectiveness, and product development activities are much more likely to achieve higher performance on effectiveness (Conant, Mokwa, and Varadarajan, 1991; Vorhies 1998). In studies of resource based view, many researchers have revealed that a firm is composed of a bundle of resources and capabilities, leading to different performance in firms (e.g., Dutta, Narasimhan, and Rajiv 1999). Dutta, Narasimhan, and Rajiv (1999) found that among the three factors of marketing capability, $R \& D$ capability, and operations capability, leading to favorable output in high-technology markets, marketing capability had the greatest impact on the performance. Song and Parry (1997) and Gatignon and Xuereh (1997) found that marketing and technological proficiency independently influence competitive advantage. Many other researches investigating marketing capabilities have revealed its effect on new product outcome (e.g., Moorman and Slotegraaf 1999). Consistently, marketing scholars have advocated that firm performance is dependent on its development of well-conceived marketing strategies and its ability to execute them (e.g., Day and Wensley 1988; Kerin, Mahajan, and Varadarajan 1990; Sashittal and Tankersley 1997; Morgan, Zou, Vorhies, and Katsikeas 2003).

Hence, we expect marketing capability will play an important mediating role between MBOL and firm performance. Especially organizational marketing capability will enhance both effectiveness and efficiency of firm performance, which market learning is not expected to be directly linked. The foregoing implies that marketing capability influences on both types of firm performance, and thus leads to the following hypothesis:

H7: Marketing capability will positively in- 
fluence both effectiveness and efficiency of firm performance

\section{Research Methodology}

\subsection{Sample and data collection}

This study employed both Web-based and mail surveys targeting marketing managers of companies within the United States, using the databases of several marketing associations, such as Medical Marketing Association, American Marketing Association and American Banking Association. Also, we collected the contact information of 500 U.S. companies' marketing executives. Medium and large sized organizations were chosen because they are more likely to have systematic intelligence processing, which in vital to a learning process. The next stage of the sampling procedure involved finding the name of a key informant. As detailed by Campbell (1955), the key informant approach enables researchers to obtain information about a group (i.e., a firm) by collecting data from selected people within that group who are highly knowledgeable about the phenomena under study. Our targeted key informants were the vice presidents of marketing within each firm. Vice presidents of marketing are ideal respondents because of their high levels of knowledge about the firm, its strategic environment, and its new product performance (Link and Bauer 1989).

Before emailing and mailing questionnaires, attempts were made to precontact each key informant to telephone to (1) assess the information's ability to serve as a key informant by asking if he or she was knowledgeable, (2) to obtain cooperation, and (3) to verify the informant's mailing address and other contact information (e.g., fax number and email). Each informant was mailed a cover letter, a one-page summary description of the study and a postage-

〈Figure 1〉 Hypothesized Model

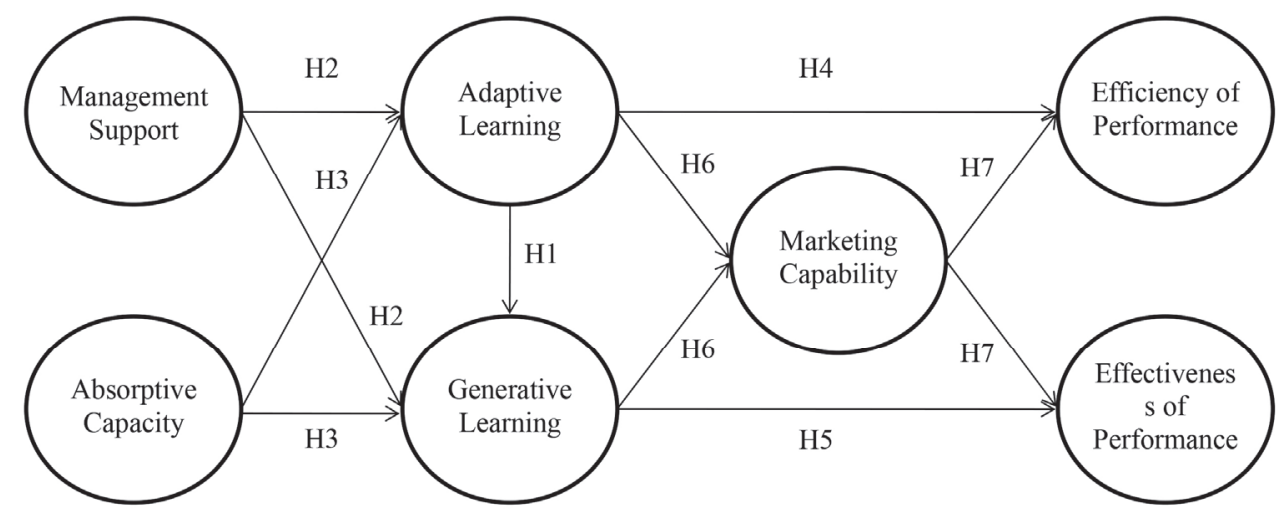


paid reply envelope. After this initial emailing, we telephoned nonrespondents and sent a hand written postcard one week later. Informants who did not reply within 6 weeks were mailed a second set of survey materials. As Armstrong and Overton (1977) recommend, potential nonresponse bias was assessed through an extrapolation method of comparing early with late respondents.

A total of 221 marketing managers out of 1,278 companies completed the surveys. This resulted in a cumulative response rate of $17.3 \%$. Of the 221 respondents, ten were excluded due to incomplete responses, leaving final sample size of $211(16.5 \%)$. In the effort to validate the sample, the marketing managers who agreed to participate in the survey completed a question requesting the participants' title, email addresses, and company name.

To assess non response bias, comparison of the first 20-25\% of the respondents from each source with the last $20-25 \%$ of the respondents from each group for all key constructs was conducted (Armstrong and Overton 1977). The results provide evidence that nonresponse bias is not a concern. The mean differences for each of focal constructs are insignificant.

The demographic characteristics of the sample are highlighted in Table 5. The majority (71.5\%) of the sample is between the ages of 30-49, and $69.2 \%$ of the sample is male. Of the informants, $46.9 \%$ were managers from marketing, $32 \%$ were CEO and vice president. These informants had a mean industry experience of 16.01 years and a mean firm experience of 9.93 years. Common method bias has been attracting increased attention in structural equation-modeling studies (MacKenzie, Podsakoff, and Rich, 2001; Podsakoff et al., 2003). The present work could suffer from CMB, as all data were collected from a single source. The traditional method for checking CMB is Harmon's single-factor test (Andersson and Bateman 1997; Aulakh and Gencturk 2000; Podsakoff, MacKenzie, and Podsakoff, 2003; Podsakoff and Organ, 1986). As such, the first factor from the exploratory factor analysis explained (24.71\%) of total variance, which is not large enough to generate concern about CMB (Podsakoff and Organ, 1986). Also, data were collected using two different kinds of measures, perceptual and objective. Therefore, CMB does not appear to be a threat to the validity of the model.

\subsection{Measures}

All the measures used in this study were drawn from existing literature and adapted to serve the purpose of this study. The measurement scales were 7-point Likert-type scales ranging from 1 (Strongly Disagree) to 7 (Strongly Agree). Some of the items were modified to better fit the context of this study. During the main study, we conducted conventional validity and reliability tests: The validity test for each measurement scale was based on confirmatory factor analysis (CFA) using LISREL 8.3. Based 
〈Table 4〉 Demographic Characteristics of the Sample $(n=211)$

\begin{tabular}{|c|c|c|c|}
\hline \multicolumn{2}{|c|}{ Variables } & Number (\%) & Mean \\
\hline \multirow{4}{*}{ Industry } & Manufacture & $95(45.0 \%)$ & N/A \\
\hline & Banking & $46(21.8 \%)$ & N/A \\
\hline & Service & $58(27.5 \%)$ & $\mathrm{N} / \mathrm{A}$ \\
\hline & Retail & $12(5 / 7 \%)$ & $\mathrm{N} / \mathrm{A}$ \\
\hline \multirow{2}{*}{ Gender } & Male & $146(69.2 \%)$ & $\mathrm{N} / \mathrm{A}$ \\
\hline & Female & $65(30.8 \%)$ & N/A \\
\hline \multirow{4}{*}{ Age } & $20 \mathrm{~s}$ & $29(13.7 \%)$ & 38.9 \\
\hline & $30 \mathrm{~s}$ & $91(43.1 \%)$ & \\
\hline & $40 \mathrm{~s}$ & $60(28.4 \%)$ & \\
\hline & $50 \mathrm{~s}$ & $31(14.7 \%)$ & \\
\hline \multirow{5}{*}{ Position } & $\mathrm{CEO}$ & $17(8.1 \%)$ & $\mathrm{N} / \mathrm{A}$ \\
\hline & V.P. & $51(24.2 \%)$ & $\mathrm{N} / \mathrm{A}$ \\
\hline & Marketing Manager & $99(46.9 \%)$ & N/A \\
\hline & CIS Manager & $42(19.9 \%)$ & N/A \\
\hline & etc & $2(0.9 \%)$ & N/A \\
\hline \multirow{3}{*}{ Work Experience } & Current position & N/A & 5.96 \\
\hline & Current company & N/A & 9.93 \\
\hline & Industry experience & N/A & 16.01 \\
\hline \multicolumn{2}{|c|}{ \# of employees } & N/A & 1627.7 \\
\hline
\end{tabular}

on the CFA results, some of the items with low factor loadings were removed from the scales. The internal reliability tests based on Cronbach's alpha showed that the measures for each construct exceed Nunnally and Bernstein's (1994) threshold value of .70 .

The measurement scale for Absorptive Capacity was adopted from Szulanski (1996) and modified for this study. Management Support which was measured with a three-item scale adapted from Park (Park 2004), resulted in adequate reliability (alpha $=.96)$. The scale for Marketing Capability was adapted from Vorheis and Morgan (2003) which demonstrated adequate reliability (alpha $=.95)$. The scale for Market-based
Organizational Leaning was adapted from Park (2004). The two sub-dimensions showed acceptable reliability (alpha $=.96$ and .95). Efficiency of performance is defined as an organization's short-term oriented general performance based on financial inputs and effectiveness of performance is defined as an organization's longterm oriented new product performance. The efficiency of performance was measured with two-item scale that captured the extent which the performance met expectation for cost and profits (Menon et al. 1996). The effectiveness of performance was measure with five-item scale that has much of its grounding in Moormans's (1995) and Moorman and Miner's (1997) work 


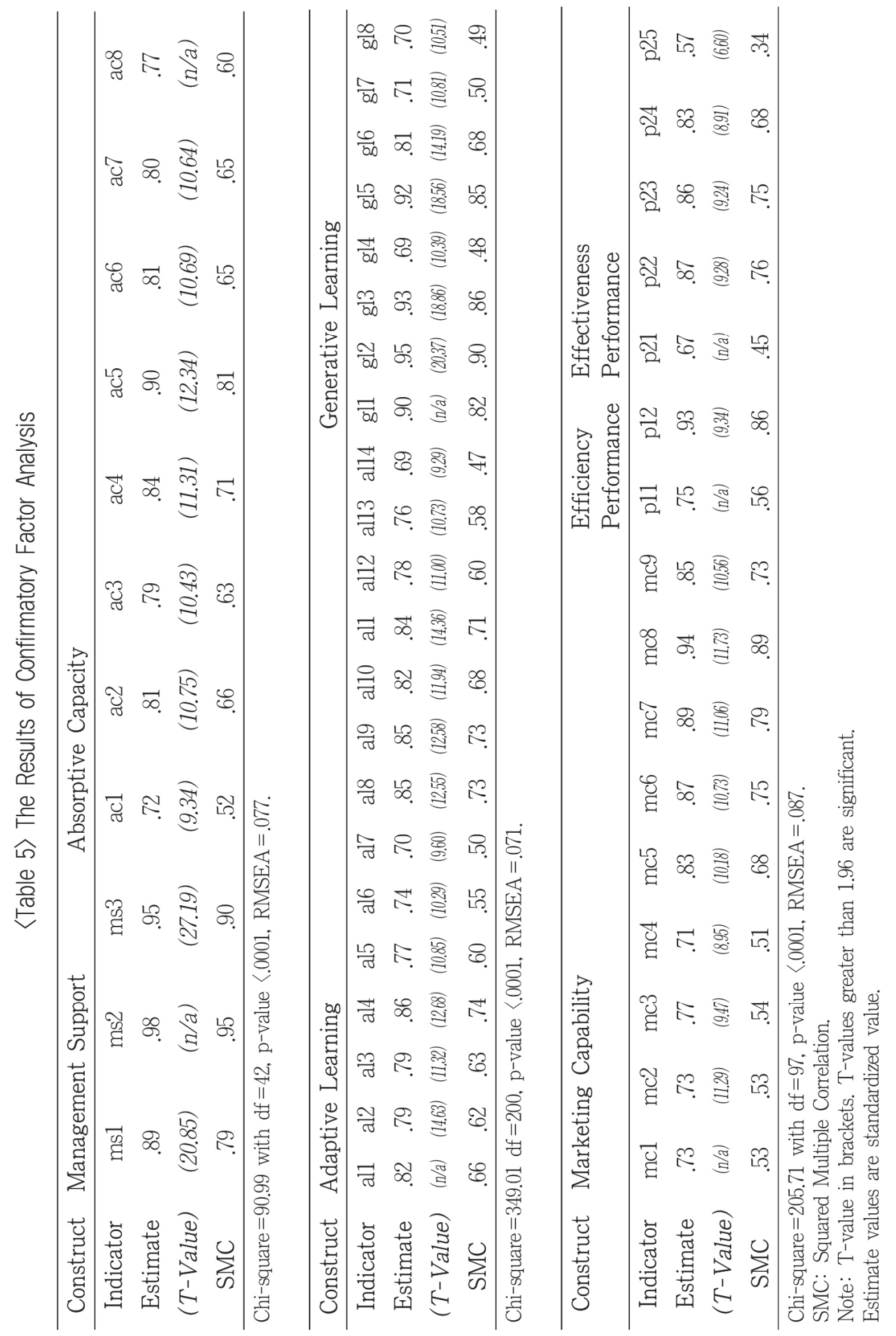

How to Build a Learning Capability for Innovation? A Framework of Market-Based Learning Process 41 
in the area of new product quality, performance, and creativity. Although objective measures may have been more ideal, recent research points out that managerial assessments of financial and market performance are consistent with objective performance measures (cf. Hart and Banbury 1994; Naman and Slevin 1993). The measurement scale for two performance dimensions which indicate effectiveness and efficiency exhibited acceptable reliability (alpha $=$ .82 for the efficiency and .87 for the effectiveness). The Appendix presents all the measures and their sources.

\subsection{Structural Model}

All constructs were evaluated on the reliability and discriminant and convergent validity (Anderson and Gerbing, 1988). Following the two-stage approach of model validation (Anderson and Gerbing, 1988), measurement validity of each construct appearing in the structural model was tested prior to estimating and testing the hypothesized structural paths. The testing model with all indicators is presented in Figure. 2. The results of the measurement models show that our selected items provide good explanations for each construct. As indicated by the results of CFA (Table 5), all items have a significant loading on their corresponding construct with the lowest $t$-value being 6.60. A pairwise comparison of the constructs in the modification indices indicated that all latent trait correlations between constructs are significantly different than one, establishing discriminant validity. Based upon the significant loading estimates and the high construct reliabilities, we established support for convergent validity (Bagozzi and Yi,

〈Table 6〉 Means, Standard Deviations, Correlations and AVE

\begin{tabular}{lcccccccccc}
\hline & 1 & 2 & 3 & 4 & 5 & 6 & 7 & Mean(Std) & AVE & Alpha \\
\hline $\begin{array}{l}\text { 1. Management } \\
\text { Support }\end{array}$ & 1.00 & & & & & & & $4.80(1.51)$ & .90 & .90 \\
$\begin{array}{l}\text { 2. Absorptive } \\
\text { Capacity }\end{array}$ & 0.73 & 1.00 & & & & & & $4.77(1.25)$ & .78 & .90 \\
$\begin{array}{l}\text { 3. Adaptive } \\
\quad \text { Learning }\end{array}$ & 0.71 & 0.73 & 1.00 & & & & & $4.73(1.11)$ & .78 & .90 \\
$\begin{array}{l}\text { 4. Generative } \\
\text { Learning }\end{array}$ & 0.63 & 0.63 & 0.67 & 1.00 & & & & $4.41(1.36)$ & .81 & .91 \\
$\begin{array}{l}\text { 5. Marketing } \\
\text { Capability }\end{array}$ & 0.64 & 0.72 & 0.58 & 0.55 & 1.00 & & & $4.59(1.18)$ & .80 & .90 \\
$\begin{array}{l}\text { 6. Efficiency } \\
\text { Performance }\end{array}$ & 0.41 & 0.45 & 0.44 & 0.46 & 0.50 & 1.00 & & $4.78(1.28)$ & .69 & .92 \\
$\begin{array}{l}\text { 7. Effectiveness } \\
\text { Performance }\end{array}$ & 0.64 & 0.68 & 0.63 & 0.59 & 0.76 & 0.68 & 1.00 & $4.89(1.09)$ & .70 & .90 \\
\hline
\end{tabular}


1988). Discriminant validity of all the latent variables was checked through $\mathrm{X}^{2}$ Difference Tests. For each pair of constructs, the restricted model (in which the correlation was fixed as one) was significantly worse than the freely estimated model (in which the correlation was estimated freely). All the latent-trait correlations between constructs were found significantly different from each other, establishing discriminant validity (Anderson and Gerbing, 1988). Information obtained from the measurement model was then used to help estimate the overall structural model. The model showed a good fit: the $x^{2}$ is not significant $\left(x^{2}=1292.62, \mathrm{df}=1025\right.$, $p=.0001)$ and the $x^{2} / d f$ ratio was below 2.0. In the structural model, the error terms of eight items within same construct were found to be highly correlated and, thus, these error terms were allowed to correlate with each other to improve the model fit. The fit indices reflected a good model fit: Comparative Fit Index (CFI) $=.965$, Normed Fit Index $(\mathrm{NFI})=.852$, Root Mean Squared Error of Approximation (RMSEA) $=.042$.

\subsection{Hypotheses Testing}

In testing the hypothesized model, we used SEM to consider explicitly the possible bias of measurement error on path estimates. Consistent with the procedures on psychology (e.g., Holmbeck 1997) and marketing (Andrew et al. 2004; Handelman and Arnold 1999; Selness and Sallis 2003), our SEMs not only account for meas-

〈Figure 2〉 Model Test Result

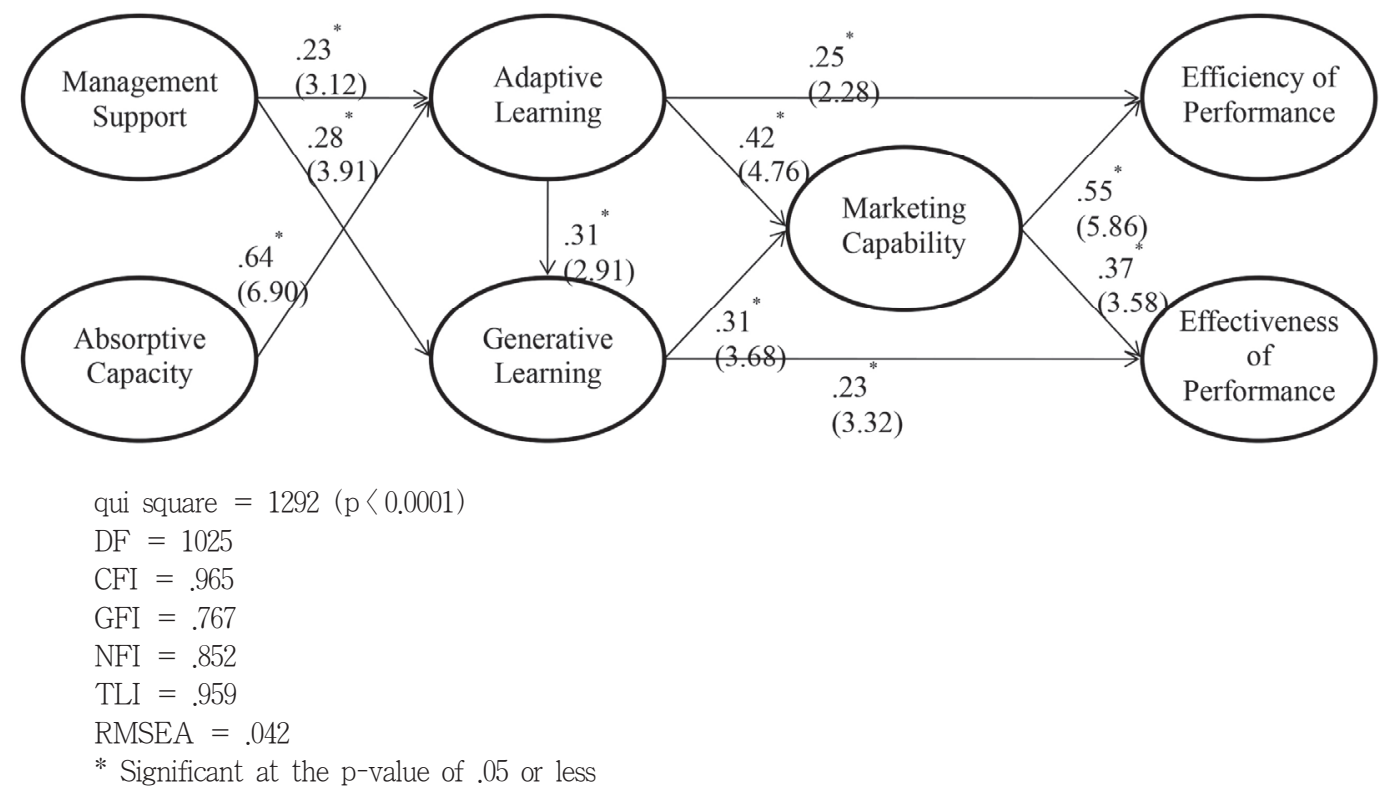

How to Build a Learning Capability for Innovation? A Framework of Market-Based Learning Process 43 
urement error but also allow for a comprehensive test of the hypotheses related to mediation.

All the results are presented in figure 2. Hypothesis 1, which proposed a positive adaptive - generative market learning relationship, was supported $(\beta=.31, t=2.91$ and $p<.01)$. Hypothesis 2, which suggested a positive relationship between management support and both types of learning, was also supported $(\beta=.23$ and $.28, t=3.12$ and 3.91 and $p<.01)$. Hypothesis 3 , which predicted a positive relationship between absorptive capacity and both types of learning, was partially supported. The result shows that absorptive capacity have positive influence only on adaptive market learning ( $\beta=$ $.64, t=6.90$ and $p<.01)$ not on generative marketing learning. Hypothesis 4 and 5, which posited the positive relationship between adaptive (generative) learning and firm's efficiency (effectiveness) performance, was supported $(\beta=$ .25 and $.23, \mathrm{t}=2.28$ and 3.32 and $\mathrm{p}<.01$ ). Hypothesis 6, which proposed a positive relationship between both types of learning and marketing capability was also supported $(\beta=$ .42 and $.31, t=4.76$ and 3.68 and $p<.01)$. Finally, hypotheses 7 , which predicted a positive relationship between marketing capability and efficiency and effectiveness performance was supported $(\beta=.55$ and $.37, t=5.76$ and 3.58 and $\mathrm{p}<.01)$.

\subsection{A mediating role of marketing capabilities}

We then sought to determine the mediating role of marketing capability between two types of learning and two types of performance. If the indirect effect of two types of learning on performance is significant or greater in comparison to the direct effect of learning on performance, this helps to demonstrate the important role of marketing capabilities in implementing market learning.

To perform this empirical test of mediation, we analyzed an additional model, adding a direct path from two types of learning to two types of performance. We then compared the chi-square values of the proposed model with those of the alternative model (Bagozzi and Yi, 1988). Chi-square difference tests showed that the addition of a direct path does not improve the fit significantly at the 0.05 level (proposed model: $x^{2}=1297.2$ with d.f. 1027 vs. alternative model: $x^{2}=1292.6$ with d.f. 1025).

In addition, we compared the magnitude of direct and indirect effects between learning and performance. The total effect of adaptive learning on two types of performance is .57 and $.36^{1)}$ each with an indirect effect of .32 and .36 and a direct effect of .25 and .11. And the total effect of generative learning on two types of performance is .28 and .34 each with

1) Indicated statistics are in order of efficiency type performance and effectiveness type performance 
an indirect effect of .17 and .11 and a direct effect of .11 and .23. Therefore, we can conclude that the indirect effect through marketing capability is more dominant than the direct effect in explaining the total effect between learning and organizational performance.

\section{Discussion and Implication}

The present study extends prior research about market learning, marketing capabilities and innovation process by exploring the relationship between market learning and firm performance. The reconceptualization of market learning and its antecedents of this study give further understanding of leaning in organization. Furthermore, we provide evidence that the intervening role of marketing capability between market learning and firm performance is more important than is currently suggested in the extant research.

Two levels of adaptive and generative learning cover the concept of other typology of learning such as exploitation vs. exploration learning (March 1991) and cognitive vs. experiential learning (Gavetti and Levinthal 2000). What is learned from market in the department is rather explicit, where as the knowledge which acquired in the department becomes more tacit when it is to be utilized in the other department. Hence adaptive learning of inter department is more involved in exploitative learning, whereas generative learning of intra department is involved in explorative learning because they need to use the knowledge which is already acquired in the other department so that the information should be processed once more according to its usage.

Cohen and Levinthal (1990) present prior knowledge as a factor driving absorptive capacity in their study. Knowledge learned through adaptive learning could become a driver of generative learning since as much knowledge they have they can apply to other department. Several of our findings offer important implications for improving learning research and practice. First, this study has undertaken a holistic examination of the learning proved by incorporating the role of its key antecedents: management support and absorptive capacity. We have found strong evidence that in much of the marketing-related research on market learning, scholars have defined the construct in a highly inconsistent way. Though prior research noted the importance of market leaning in innovation or sustainability there has been lack of rigorous investigation of the market learning (Vorhis and Morgan 2003). Moreover, drawing on the two level of market learning framework allows us to gain insights when applied to the learning organization. As such, this represents the first attempt to conceptualize two levels of and learning from a marketing perspective (effectiveness and efficiency).

Second major goal of this research was to 
suggest that the value of marketing capability in market learning and performance relationship. From substantive perspective, this paper contributes to the marketing literature by emphasizing the role played by marketing capability at the final stage of the innovation process. The study's findings support the notion that both innovativeness and economic performance are achieved through marketing capability --- firms that have marketing capability may enjoy competitive advantage in both type of performance. And it happens when they have orientation of market learning. In other words, the hole process of market learning and building marketing capability represents the innovation process achieving both innovation and economic performance.

Our results also seem to support the relationship between market learning and performance. We find empirical support for the different effect of the two levels of market learning on firm performance. Prior research investigating the influence of market learning has tended to investigate the combined impact of market learning ignoring their independent effect. Such approaches are fruitful as a first step toward understanding deeply the nature of the role of market learning. Specifically, this study suggests that adaptive learning process is rather micro perspective and short term oriented learning whereas the generative learning process is rather macro and long term oriented learning. Hence we concluded those two types of learning will influence firm performance differently.
Adaptive learning will enhance only short term level of performance which we can say 'efficiency of performance'. On the other hand, generative learning will have a positive impact only on 'effectiveness of performance'.

Finally the results of this study suggest that absorptive capacity and management support are important determinant of market learning. Many of market learning researchers have emphasized the important role of organizational culture and support in order to build efficient learning capability. Our research confirmed the wisdom of these previous studies with more rigorous variables and data. The results also suggest that market learning and absorptive capavity are distict construct. Market learning emphasizes the organizational value and intention of obtaining knowledge and utilizing it, whereas absorptive capacity focuses on the organizations' support for market learning. If absorptive capacity is considered as the input, then market learning can be viewed as the output of their efforts. Hypothesis 2 which proposes the positive relationship between absorptive capacity and generative learning turned out to be insignificant path statistically. The reason is that absorptive capacity is what organization support whereas generative learning is what the members of organization does the influence of absorptive capacity may be very limited to the explicit, intra departmental level of learning.

This study also suggests a couple of important managerial implications for marketing managers. 
Foremost, our study suggests that managers should be aware of the importance of marketing capabilities in the link or market learning and firm performance. Firms can amplify and enlarge knowledge through the dynamic conversion between tacit and explicit knowledge. Managers have to facilitate dynamics and spiral of learning by taking a leading role in managing hole innovation process. They need to nurture an enabling environment that allows employees to share and exchange tacit knowledge to create new knowledge.

On the other hand, our study also cautions managers that the impact of learning behavior without marketing capability is limited to the only one side of performance. All organization learn, for better or worse, and the challenge is to understand the pattern of organizational learning and manage it with its context, according to their final goal. For instance, organization engaging only adaptive learning behavior may achieve only economic performance. If managers intend to take advantage of market learning, they must work to develop marketing capability in the organization that would let focus on both innovativeness and economic performance.

This offers critical insights to management. Market learning facilitates the generation of resources and skills essential for firm performance. The findings also suggest that market learning is central not only for innovation but also for the organization's other activities.

Second, management should promote a culture within the organization that fosters learning. A learning culture within the marketing function is likely to improve the availability and quality of customer information within the firm and provides a valuable mechanism to infuse learning behaviors throughout the organization (Chonko et al., 2000; Hult, 1998). They should provide incentive and support to reinforce the desired behaviors of market learning behavior. Employees will be motivated to exchange, learn, and create new knowledge and further transform what has learned to fulfill firm's objectives and execution. As shown in the results of empirical study, absorptive capacity influences adaptive learning very strongly. Hence, managers who want to encourage learning, need to build up this absorptive capacity on their organization.

Third, the whole model shows how to obtain competitive position in both efficiency and effectiveness of performance in the market. A firm with marketing capability can more easily achieve higher position in both types of performance which we refer "ambidextrous organization" whereas two types of learning can achieve only one side of performance. Therefore it gives implication of the importance of cultivating marketing capability through MBOL.

In conclusion, it is hoped that this research contributes to both academicians and business practitioners by improving our understanding of learning process and its related constructs. The primary objective of this study was to build up conceptual framework of MBOL and 
its key determinants and consequences. In conceptualizing MBOL, we identified there exist two types of learning which we indicated as adaptive vs. generative learning. Here we proposed and empirically tested an important concept of marketing capability which works as a mediator between MBOL and firm performance. Organizations that have built marketing capability through MBOL will be able to enjoy high performance of both effectiveness and efficiency.

\section{Limitations}

The paper also suffers from a numbers of limitations that provide opportunities for future research. First, this study emphasizes the importance of market learning and marketing capabilities and links them with efficiency (economic) performance and effectiveness (innovation) performance, but it does not address the issue of information type. Future research could identify how market learning occurs depend on knowledge or information type as either antecedents or boundary condition. Second, this study is limited to the effect of top management support as cultural factor influencing market learning, but other factors (i.e., levels of autonomy) can be applied in the future study. Third, future research might consider other control variables which are already known from literature on MBOL.

Because these bodies of literature are $\mathrm{ex}^{-}$ tremely broad and drawing much from outside of marketing, other researchers might reach alterative conceptualizations regarding MBOL and its antecedents. Given the limited empirical evidence regarding $\mathrm{MBOL}$, the assessment of its benefits and the development of a clear understanding of the processes of MBOL and the management practices that facilitate or hinder market learning should be a high priority.

〈Received December 1. 2014〉

〈Revised January 2. 2015〉

〈Accepted April 13. 2015〉

\section{References}

Alegre, J. and Chiva, R. (2008). Assessing the Impact of Organizational Learning Capability on Product Innovation performance: An Empirical Test. Technovation 28: 315326.

Andersson, L. M., and Bateman, T. S. (1997). Cynicism in the workplace: some causes and effects. Journal of Organizational Behavior 18: 449-469.

Aulakh, P. S., and Gencturk, E. F. (2000). International principal-agent relationships -control, governance and performance. Industrial Marketing Management 29: 521-538. 
Argyris, C. and Schön, D. A. (1978). Organizational Learning: A Theory of Action Perspective, Reading. MA: Addison-Wesley.

Bagozzi, R. P., and Yi, Youjae (1988). On the evaluation of structural equation models," Journal of the Academy of Marketing Science 16 (1): 74-94.

Baker, W. E. and Sinkula, J. M. (1999). The Synergistic Effect of Market Orientation and Learning Orientation on Organizational Performance. Journal of the Academy of Marketing Science. 27 (4): 411-427. and (2007). Does

Market Orientation Facilitate Balanced Innovation Programs? An Organizational Learning Perspective) Journal of Product Innovation Management, 24, 316-34.

Barczak, G., and. Crossan, M. (1995). New Product Strategy, Structure, Process, and Performance in the Telecommunication Industry. Journal of Product Innovation Management 12: 224-234.

Barney, J. B (1986) Strategic Factor Markets: Expectations, Luck and Business Strategy," Management Science 32 (10): 1231-1241. (1991). Firm Resources and Sustained Competitive Advantage. Journal of Management 17 (1): 99-120.

Bateson, G. (1972). Steps to an Ecology of Mind. New York: Ballantine Books

Bell, S. J., Whitwell, G. J. and Lukas, B. A. (2002). Schools of Thought in Organizational Learning. Journal of the Academy of Marketing Science 30 (1): 70-86.

Bennett, J. K and O’Brien, M. J. (1994). The building Blocks of the Learning Organization. Training, 31 (6): 41-49.

Brockman, B. K. and Morgan, R. M. (2003). The Role of Existing Knowledge in New Product Innovativeness and Performance. Decision Science 34 (2): 385-419.

Chonko, L. B., Jones, J., Roberts, A., and Dubinsky, A. J. (2002). The Role of Environmental Turbulence, Readiness for Change, and Salesperson Learning in the Success of Sales Force Change. Journal of Personal Selling and Sales Management 22 (4): 227-238.

Claycomb, V. and Miller, S. J. (1999). The Relationship between Market-based Organizational Learning Orientation and Organizational Structure across Various Contingency Variables. The Journal of Marketing Management (Summer/Fall) : 1-18.

Cohen, W. M. and Levinthal, D. A. (1990). Absorptive Capacity: A New Perspective on Learning and Innovation. Administrative Science Quarterly 35 128-152.

Conant, J. S., Mokwa, M. P., and Varadarajan, P. R. (1990). Strategic Types, Distinctive Marketing Competencies and Organizational Performance: A Multiple Measures-Based Study. Strategic Management Journal. 11 (5): 365-83.

Crossan, M. M., Lane, H. W. and White, R. E. (1999). An Organizational Learning Frame- 
work: From Intuition to Institution. Academy of Management Review, 24(3) : 522537.

Day, G. S. (1990), Market Driven Strategy: Processes for Creating Value. New York: Free Press.

(1994), "Continuous Learning about Markets," California Management Review, 36 (4) : 9-31.

(1988). Assessing Advantage:

A Framework for Diagnosing Competitive Superiority. Journal of Marketing 52 (April) : $1-20$.

De Geus, A P. (1988). Planning as Learning. Harvard Business Review 66 (March/April): 70-74.

Deshpandè, R. (1999). Introduction," in Developing a Market Orientation. Rohit Deshpande, ed. Thousand Oaks, CA: Sage Publications, $1-6$. , Farley, J. U., and Webster Jr. F. E, (1993). Corporate Culture, Customer Orientation, and Innovativeness in Japanese Firms: A Quadrad Analysis. Journal of Marketing 57 (1): 23-37. and Webster, F. E., Jr. (1989). Organizational Culture and $\mathrm{Ma}^{-}$ rketing: Defining the Research Agenda. Journal of Marketing 53 (January): 3-15.

Dickson, P. R. (1992). Toward a General Theory of Competitive Rationality. Journal of Marketing 56 (January) : 69-83. (1996). The Static and Dynamic
Mechanics of Competition: A Comment on Hunt and Morgan's Comparative Advantage Theory. Journal of Marketing 60 (October): 102-06.

(2003). Creating a Superior CustomerRelating Capability. MIT Sloan Management Review 44 (3) : 77-82. and Wensley, R(1988). Assessing advantage: A framework for diagnosing competitive superiority. Journal of Marketing 52 (April) : 1-20.

Dixon, N. M. (1992). Organizational Learning: A Review of the Literature with Implications for HRD Professionals. Human $\mathrm{Re}^{-}$ source Development Quarterly 3 (Spring): 29-49.

Dutta, S., Narasimhan, O. and Rajiv S. (1999). Success in High-Technology Markets: Is Marketing Capability Critical? Marketing Science 18 (4) : 547-568.

Farrell, M. A. (2000). Developing a MarketOriented Learning Organization. Australian Journal of Management 25(2): 201-322.

Fiol, C. M., and Lyles, M. A. (1985). Organizational Learning. Academy of Management Review 10(4): 803-813.

Garvin, D. A. (1993). Building a Learning Organization. Harvard Business Review July-August: 78-91.

Grant, R. M. (1996). Prospering in DynamicallyCompetitive Environments: Organizational Capability as Knowledge Integration. Organization Science 7 (July): 375-387. 
Griffin, A. (1997). PDMA Research on New Product Development Practice: Updating trends and Benchmarking Best Practices. Journal of Product Innovation Management 14(6): 429-259.

Hanvanich, S., Sivakumar, K., and. Hult, G. T. M. (2006). The Relationship of Learning and Memory with Organizational Performance: The Moderating Role of Turbulence. Journal of the Academy of Marketing Science 34 (3) : 600-12.

Hedberg, B. (1981). How Organizations Learn and Unlearn. In: Handbook of Organizational Design, ed. Paul C. Nystrom and William H. Starbuck. New York: Oxford, University Press. 3-27.

Huber, G. P. (1991). Organizational Learning: The Contributing Processes and the Literatures Organization Science 2 (1): 88-115. Hunt, S. D. and Morgan, R. M. (1996). The Resource- Advantage Theory of Competition: Dynamics, Path dependencies, and Evolutionary Dimensions. Journal of Marketing 60 (October) : 107-14.

Hurley, R. F. and Hult, G. T. M. (1998). Innovation, Market Orientation, and Organizational Learning: An Integration and Empirical Examination. Journal of Marketing 62 (July) : 42-54.

Kale, P. and Sigh H. (2007). Building Firm Capabilities through Learning: The Role of the Alliance Learning Process in Alliance Capability and Firm-Level Alliance Success.
Strategic Management Journal 28: 9811000.

Kohli, A. K. and Jaworski, B. J.(1990). Market Orientation: The Construct, Research Propositions, and Managerial Implications. Journal of Marketing 54 (April): 1-18.

Marinova, D. (2004). Actualizing Innovation Effort: The Impact of Market Knowledge Diffusion in a Dynamic System of Competition. Journal of Marketing 68 (July): 1-20.

MacKenzie, S. B., Podsakoff, P. M., and Rich, G. A. (2001). Transformational and transactional leadership and salesperson performance. Journal of the Academy of Marketing Science 29 (2): 115-134.

McKee, D. (1992). An Organizational Learning Approach to Product Innovation. Journal of Product Innovation Management 9 (September): 232-245.

Methe, D. T., Toyoma, R.and Miyabe J. (1997) Product Development Strategy and Organizational Learning: A Tale of Two PC Market. Journal of Product Innovation Management 14: 323-336.

Michael, S. C., and Palandjian, T.P., (2004). Organizational Learning and New Product Introduction. Journal of Product Innovation Management 21(4): 268-276.

Moorman, C. (1995). Organizational Market Information Processes: Cultural Antecedents and New Product Outcomes. Journal of Marketing Research 32 (August): 318-335. 
and Miner, A. S. (1997). The Impact of Organizational Memory on New Product Performance and Creativity. Journal of Marketing Research, 34: 91-106.

Morgan, N. A., Zou, S., Vorhies, D. W., and Katsikeas C. S., (2003). Experiential and Informational Knowledge, Architectural Mark eting Capabilities, and the Adaptive Performance of Export Ventures: A CrossNational Study. Decision Sciences 34 (2): 287-321.

Morgan, R. M. and Hunt, S. D. (1994). The Commitment-Trust Theory of Relationship Marketing. Journal of Marketing 58 (July): 20-38.

Mowery D., Oxley, J., and Silverman, B. (1996). Strategic Alliances and Interfirm Knowledge Transfer. Strategic Management Journal 30: 77-92.

Noble, C. H., Sinha, R. K., and Kumar, A. (2002). Market Orientation and Alternative Strategic Orientations: A Longitudinal Assessment of Performance Implications. Journal of Marketing 66: 25-39.

Nonaka, I. (1991). The Knowledge Creating Company. Harvard Business Review 69 (6): 96-104.

(1994). A Dynamic Theory of Organizational Knowledge Creation. Organization Science 5 (1): 14-37.

O'connor, G. C.(1998). Market Learning and Radical Innovation: A Cross Case Comparison of Eight Radical Innovation Projects.
Journal of Product Innovation Management 15(2): 151-166.

Özsomer, A., and Gençtürk, E. (2003). A Resource-Based Model of Market Learning in the Subsidiary: The Capabilities of Exploration and Exploitation. Journal of International Marketing 11 (3): 1-29.

Paladino, A. (2007). Investigating the Drivers of Innovation and New Product Success:

A Comparison of Strategic Orientations. Journal of Product Innovation Management 24: 534-553.

Park, J. E. (2004). The Impact of Marketing Outsourcing on the Market-based Organizational Learning Process. Doctoral Dissertation. The University of Alabama.

Podsakoff, P. M., MacKenzie, S. B., Lee, J. and Podsakoff, N. P. (2003). Common method biases in behavioral research: a critical review of the literature and recommended remedies. Journal of Applied Psychology 88 (5) : 879-903.

Saban, K., Lanasa, J., Lackman, C., and Peace, G. (2000). Organizational Learning: a Critical Component to New Product Development. Journal of Product and Brand Management 9 (2) : 99-119.

Sinkula, J. M. (1994). Market Information Processing and Organizational Learning. Journal of Marketing 58 (January): 35-45. , Baker ,W., and Noordewier, T (1997). A Framework for Market-Based Organizational Learning: Linking Values, 
Knowledge, and Behavior. Journal of the Academy of Marketing Science 25 (4): 305-319

Slater, S. F. and Narver, J. C. (1995). Market Orientation and the Learning Organization Journal of Marketing 59 (July): 63-74.

Szulanski, G. (1996). Exploring Internal Stickiness: Impediments to the Transfer of Best Practice within the Firm. Strategic Management Journal 17: 27-43.

Vorhies, D. W., Harker, M., and Rao, C.P (1998). The Capabilities and Performance Advantages of Market-Driven Firms. European Journal of Marketing 33 (11/12):1171-1202. and Morgan, N. A. (2003). A Configuration Theory Assessment of Marketing Organization Fit with Business Strategy and Its Relationship with Marketing Performance. Journal of Marketing 67 (January) : 100-115. and (2005). Benchmarking Marketing Capabilities for Sustainable Competitive Advantage. Journal of Marketing 69 (January): 80-94.
Wakasugi, R. and Koyata, F. (1997). R\&D, Firm Size and Innovation Outputs: Are Japanese Firms efficient in Product Development? Journal of Product Innovation Management 14(5): 383-393.

Walker, O. C. and Ruekert, R. W. (1987). Marketing's Role in the Implementation of Business Strategies: A Critical Review and Conceptual Framework. Journal of Marketing 51 (July): 15-33.

Webster, F. E. Jr. (1992). The Changing Role of Marketing in the Corporation. Journal of Marketing 56 (October): 1-17.

Weerawardena, J. (2003). Exploring the Role of Market Learning Capability in Competitive Strategy. European Journal of Marketing 37 (3/4): 407-429.

Zhou, K. Z., Yim, C. K. and Tse, D. K. (2005). The Effects of Strategic Orientations on Technology- and Market-Based Breakthrough Innovations. Journal of Marketing 69 (April): $42-60$. 